\title{
Knowledge and attitude of anganwadi workers regarding oral health of children in ICDS project Dansal, Jammu and Kashmir
}

\author{
Rimsha Ahmed ${ }^{1}$, Rudra Kaul ${ }^{2}$, Vibhuti Kaul ${ }^{3, *}$, Sandip Rajan ${ }^{4}$ \\ ${ }^{\mathbf{1 , 4}}$ Senior Lecturer, ${ }^{2}$ Lecturer, ${ }^{3}$ Registrar, ${ }^{\mathbf{D}}$ Dept. of Prosthodontics and Crown \& Bridge, ${ }^{2}$ Dept. of Conservative Dentistry and \\ Endodontics, ${ }^{3}$ Dept. of Oral Medicine and Radiology, ${ }^{1}$ Mithila Minority Dental College and Hospital, Darbanga Bihar, ${ }^{2,3}$ Indira \\ Gandhi Government Dental College and Hospital, Jammu, Jammu \& Kashmir, ${ }^{4}$ Vardhman Mahavir Medical College and \\ Safdarjung Hospital, Delhi, India
}

*Corresponding Author:

Email: kaulvibhuti@yahoo.com

\begin{abstract}
Anganwadi workers in rural India are believed to be the first care givers to new mothers and infants. Hence, assessment of their knowledge and educating them regarding infant oral health care is of immense importance. The aim of this study was to assess knowledge, attitude and practices (KAP) regarding oral health, oral hygiene and dental caries among anganwadi workers (AWWs) of ICDS project Dansal.
\end{abstract}

Keywords: Oral health, Oral hygiene, Anganwadi workers.

\section{Introduction}

In young children, one of the most serious health conditions is poor oral health in early childhood. ${ }^{1}$ Oral health is an essential and leading component of children's overall health. Due to their developmental dependency, young children constitute a special population requiring attention and consideration of society and its governmental policymakers. ${ }^{2}$

Globally, in the children aged 3-6 years dental caries is categorized as a major public health issue. ${ }^{3}$ The lack of availability and affordability of oral health services especially in developing countries like India not only results in aggravation of the disease but also enhances the cost of treatment and care. It has been observed across various countries that the basic health care workers and parents have limited knowledge about causes and prevention of the most common oral diseases. ${ }^{4-7}$ Control of oral diseases is only possible if services are oriented towards primary health care and prevention.

Anganwadi workers (AWW), the grass root workers (serves around 1000 population per AWW) have successfully demonstrated their useful role in developing healthy habits in early childhood viz. correct brushing techniques and hand washing through non-formal education methods (learning by play way method). ${ }^{8}$ At the anganwadis, monthly meeting of mothers serve a platforms for imparting health education to mothers regarding immunization, breast feeding, institutional delivery, postnatal care etc. Empowering community workers like AWW in oral health, and providing basic oral health awareness to the mothers through them can be feasible model for a developing country like India; where oral health is not a priority in the primary health care as yet.

\section{Materials and Methods}

All the AWWs who were working in ICDS project Dansal and ready to participate in the study were included. The study was a descriptive, cross-sectional questionnaire survey. The study population included all the 203 AWWs of Dansal project. Necessary data and permission were obtained from the child development project officer, Dansal and the concerned department after explaining the procedure clearly. Informed consent was obtained from all the AWWs.

A specially designed questionnaire consisting of 18 questions was put together. It was designed for recording all the relevant data pertaining to general information, as well as contained questions related to knowledge and attitude regarding the oral health of children aged 0-6 years. The questionnaire was first prepared in English using simple layman language. It was later translated to the Hindi language for easy comprehension of the AWW. Further, the questionnaire was back-translated into English to check for any inconsistencies between the translated forms.

The data were entered into an Excel worksheet and analysis was done by using the Statistical Software SPSS version 17.0 (SPSS Statistics for Windows, Version 17.0. Chicago SPSS Inc. Released 2008). Descriptive statistics was used to summarize the results.

\section{Results}

A total of 203 AWWs responded to the questionnaire. It can be seen from Graph 1, a majority, i.e. $92.38 \%$ had an education level up to high school whereas about $7.7 \%$ of AWWs were graduates. It can be appreciated from Table 1 that $17.24 \%$ of the AWWs knew the appropriate eruption time for the first milk tooth, whereas only $12.80 \%$ AWWs were aware that baby's mouth must be cleaned even before the eruption of first milk tooth. Only $0.03 \%$ AWWs knew that the child should be taken for first dental visit before or 
within 1 year of age. About $48 \%$ of the AWW discuss the child's oral health with parents during home visits. $52 \%$ of AWWs were of the opinion that milk teeth are not important.

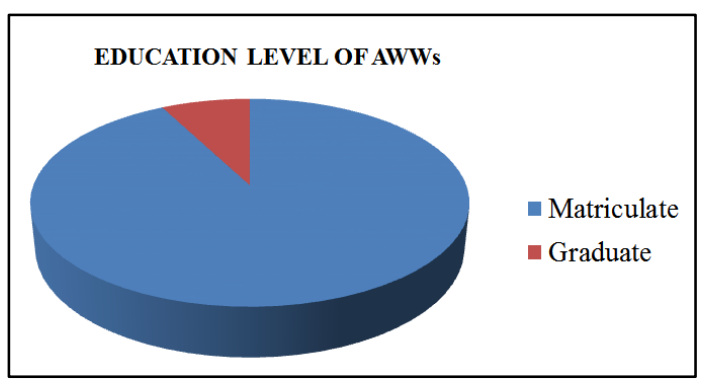

Fig. 1:

Table 1:

\section{Questions related to knowledge}

How many times in a day teeth should be cleaned?

a. Once- $147(72.41 \%)$

b. Twice- $56(27.58 \%)$

c. Never-0 (0\%)

1. Regular tooth brushing results in reduction of?

a. Dental cavities - $193(95.07 \%)$

b. Oral mucosal ulceration- $3(0.01 \%)$

c. Swelling-6 $(0.02 \%)$

d. Oral cancer-1 $(0.004 \%)$

2. What cleaning aids do you suggest for use with the toothbrush to clean teeth?

a. Toothpaste- $134(66 \%)$

b. Toothpowder-51 (25.12\%)

c. Others- $18(0.08 \%)$

3 . For how much time should teeth be cleaned?

a. $0-1$ minute $-99(48.76 \%)$

b. $1-2$ minutes $-83(40.885 \%)$

c. $3-5$ minutes $-2(10.34 \%)$

4. Foods causing tooth decay

a. Sweets/Chocolates/Toffees- $134(66 \%)$

b. Milk-9 $(0.045 \%)$

c. Biscuits-57 $(20.07 \%)$

d. Fruits-3 (0.01\%)

5. When does the first milk tooth erupt in a child's oral cavity?

a. 3 months-5 $(0.02 \%)$

b. 6 months $-110(54.18 \%)$

c. 1 year-84 $(41.37 \%)$

d. 18 months- $4(0.019 \%)$

6. Age of complete eruption of milk teeth

a. 1.5 years- $34(16.74 \%)$

b. 2 years $-67(33 \%)$

c. 2.5 years $-56(27.58 \%)$

d. 3 years $-35(17.24 \%)$

e. 4 years- $11(0.05 \%)$

7. What time is appropriate to start cleaning baby's mouth?

a. Before eruption of 1milk tooth-26 (12.80\%)

b. After eruption of 1 milk tooth-34 (16.74\%)

c. After eruption of 5-6 teeth-67 (33\%)

d. After eruption of all the teeth-76 (37.43\%)

8. Best time to take child for 1dental visit

a. Before or within 1 year of age-7 $(0.03 \%)$

b. After 1 year of age-6 $(0.02 \%)$

a. After all the teeth erupt-33 (16.25\%)

\section{Questions related to attitude}

10. Will poor oral health with several decayed teeth in a child; affect his/her growth and body weight?

a. Strongly agree-54 $(26.6 \%)$

b. Agree-42 (20.68\%)

c. Uncertain-89 $(43.84 \%)$

d. Disagree-10 $(0.049 \%)$

e. Strongly disagree- $8(0.039 \%)$

11. Putting a child to bed with sweetened milk in a bottle is okay for child's teeth

a. Strongly agree-75 (36.94\%)

b. Agree- $98(48.27 \%)$

c. Uncertain-19 $(0.093 \%)$

d. Disagree-7 (0.03\%)

e. Strongly disagree-4 $(0.019 \%)$

12. Do you feel you need more information/training to create more awareness regarding oral health among children and parents?

a. Strongly agree-12 $(0.059 \%)$

b. Agree-66 (32.51\%)

c. Uncertain-23 (11.33\%)

d. Disagree-45 (22.16\%)

e. Strongly disagree-57 $(28.07 \%)$

13. AWW has an important role to play in the maintenance of the child's oral health

a. Strongly agree-39 (19.21\%)

b. Agree-78 (38.42\%)

c. Uncertain-45 $(22.16 \%)$

d. Disagree-40 (19.70\%)

e. Strongly disagree-1 $(0.004 \%)$

14. Dental checkups must be integrated with the general health checkups for the anganwadi children a. Strongly agree-96 (47.29\%)

b. Agree-45 (22.16\%)

c. Uncertain-37 (18.22\%)

d. Disagree-25 $(12.31 \%)$

e. Strongly disagree-0 $(0 \%)$

15. Do you advise the children to brush their teeth twice daily?

a. Yes-45 (22.16\%)

b. No-158 $(77.83 \%)$

16. Do you check whether the child gargles his/her mouth with water after meals/snacks?

a. No $-9 \quad(0.044 \%)$

b. Yes-194 (95.56\%)

17. Do you discuss about the child's oral health with 


\begin{tabular}{|l|l|}
\hline b. Between 3 and 5 years of age-157 (77.33\%) & parents during home visits? \\
9. The role of milk teeth & a. Yes, always-18 $(0.088 \%)$ \\
a. As permanent teeth erupt subsequently, milk teeth & b. Sometimes-96 (47.29\%) \\
$\begin{array}{l}\text { are not important-106 (52.21\%) } \\
\text { b. Unhealthy milk teeth will have adverse effect on } \\
\begin{array}{l}\text { permanent teeth that will erupt later-34 } \\
(16.74 \%)\end{array}\end{array}$ & \\
c. Don't know- $63(31.03 \%)$ & \\
\hline
\end{tabular}

\section{Discussion}

The surgeon general of the United States public health service during 2002-2006, called oral diseases "a silent epidemic" that is "affecting most vulnerable citizens" - children from families with low incomes, children from racial and ethnic minority groups, and children with special health care needs. ${ }^{9}$ Children who suffer from poor oral health are 12 times more likely to have restricted activity - days than those who do not. More than 50 million school hours are lost annually because of oral health problems, which affect children's performance at school and success in later life. ${ }^{10}$

For optimal oral health, oral hygiene habits should be instilled at a very young age itself. ${ }^{11}$ Practices promoting awareness about health and valuing it should be developed early during the pre-school years, that is, when the children are able to absorb the information enough to incorporate oral health care into their daily life habits. ${ }^{12}$

There were 203 AWCs in Dansal project and all the AWWs participated in the study, which itself makes their positive outlook and interest with regard to the oral health of children, very evident.

In the present study, $54.18 \%$ of the AWW knew the appropriate eruption time for the first milk tooth and only $17.9 \%$ of them knew the age of complete eruption of milk teeth. In a study conducted by Mani et al. ${ }^{13}$ on caretakers of children attending day-care centers, $91.2 \%$ of the study subjects knew the eruption timing of the first baby tooth and $70.6 \%$ of the subjects were aware of the age of complete eruption of milk teeth. Only $12.80 \%$ AWWs were aware that baby's mouth must be cleaned even before the eruption of first milk tooth. Similar findings have been found in a study by Chan et al., ${ }^{14}$ where only $44 \%$ of the caregivers suggested that the oral cavity of an infant should be cleansed from birth.

About $0.03 \%$ AWWs knew that child should be taken for first dental visit before or within 1 year of age. In a study by Kranz et al. ${ }^{15}$ in North Carolina on the oral health activities of teachers in early head start (EHS) program, a federally funded program designed to address the social, educational and health needs of pregnant women and children younger than 3 years of age; about $48 \%$ EHS teachers knew the age when first dental visit is recommended.

Only $84 \%$ of the AWW knew that poor oral health, with several decayed teeth in a child will affect his/her growth and body weight. In a study by Schroth et al., ${ }^{17}$
$16.74 \%$ of the caregivers knew that rotten teeth could affect a child's health.

Responding to the question assessing knowledge about the role of milk teeth, $16.74 \%$ of the AWW said that unhealthy milk teeth will have an adverse effect on permanent teeth that will erupt later. On the contrary, in the study by Poornima et al., ${ }^{20} 64.7 \%$ of the AWW agreed that there is no need to take care of milk teeth, because they will fall after some time.

A majority, about $19.21 \%$ AWW agreed that they have an important role to play when it comes to the oral health of children. This finding is similar to the study by Dawani et al., ${ }^{22}$ where almost all preschool teachers (98\%) realized their responsibility towards assessing student's oral hygiene. Around $72.41 \%$ AWW reported to have advised the children to brush their teeth once daily and $95.56 \%$ of the workers checked whether the child gargles his/her mouth with water after meals/snacks. In a study by Vinay et al. ${ }^{23}$ only $51.36 \%$ of caretakers frequently made children rinse their mouth with water after every meal and Mani et al. ${ }^{13}$ reported that only $42 \%$ the subjects who were caretakers encouraged drinking plain water after every feed at all times.

Only $48 \%$ of the AWW reported having discussed the child's oral health with parents during home visits. Similarly, according to a study by Kranz et al. ${ }^{15}$ only $15-35 \%$ of the EHS teachers reported of routinely engaging in any of the listed parent activities related to oral health.

One of the limitations of the study could be that there was an unequal distribution of AWWs in the education and experience groups. Furthermore, there could be scope for recall bias, where the respondent's older experiences would have influenced her memory. One of the main strengths of this study was that it succeeded in turning the attention of AWWs of Dansal toward the oral health of children, and a large amount of information was collected through the close-ended questionnaire, which can be of immense use in planning an oral health programme for the AWWs.

\section{Conclusion}

Overall knowledge of the anganwadi workers about oral health was fair. The AWWs play a pivotal role in promoting general health of women and children. This force can also become a vital link in communicating oral health awareness in children and parents. For this, topic of oral health should be included 
in the curriculum of AWWs and proper training and skills should be developed through effective program on oral health by the government with the help of dentists.

\section{References}

1. Naidu R, Nunn J, Forde M. Oral healthcare of preschool children in Trinidad: A qualitative study of parents and caregivers. BMC Oral Health 2012;12:27.

2. Edelstein BL. Dental care considerations for young children. Spec Care Dent 2002;22:115-25.

3. World Health Organization: World Oral Health Report 2003. Geneva: WHO;2003.

http://www.who.int/oral_health/media/en/orh_report03_e n.pdf. Accessed on July 15, 2010.

4. Chan SC, Tsai JS, King NM: Feeding and oral hygiene habits of preschool children in Hong Kong and their caregivers' dental knowledge and attitudes. Int J Paediatr Dent 2002, 12(5):322-331.

5. Rwakatema DS, Ng'ang'a PM: Oral health knowledge, attitudes and practices of parents/guardians of pre-school children in Moshi, Tanzania. East African Med J 2009, 86(11):520-525.

6. Mahmoud K, Al Omiri MK, Board J, Ahed M, AlWahadni AM, Khaled N, Saeed KN: oral health attitudes, knowledge, and behavior among school children in North Jordan. J Dent Educ 2006, 70(2):179-187.

7. Kaur B: Evaluation of oral health awareness in parents of preschool children. Ind J Dent Res 2009, 20:463-465.

8. Guideline on Infant Oral Health Care. Originating Committee Clinical Affairs Committee - Infant Oral Health Subcommittee. 2012.

9. U.S. Department of Health and Human Services. National call to action to promote oral health. Rockville, MD: U.S. Department of Health and Human Services, Public Health Service, National Institutes of Health, National Institute of Dental and Craniofacial Research; 2003. NIH Publication No. 03-5303.

10. Kwan SY, Petersen PE, Pine CM, Borutta A. Healthpromoting schools: An opportunity for oral health promotion. Bull World Health Organ 2005;83:677-85.

11. Nair MK, Renjit M, Siju KE, Leena ML, George B, Kumar GS. Effectiveness of a community oral health awareness program. Indian Pediatr 2009;46 Suppl: S8690.

12. Antunes Ldos S, Antunes LA, Corvino MP. Educative practices and attitudes within the pre-school environment: Evaluating the education professionals. Braz Oral Res 2008;22:340.

13. Mani SA, Aziz AA, John J, Ismail NM. Knowledge, attitude and practice of oral health promoting factors among caretakers of children attending day-care centers in Kubang Kerian, Malaysia: A preliminary study. J Indian Soc Pedod Prev Dent 2010;28:78-83.

14. Chan SC, Tsai JS, King NM. Feeding and oral hygiene habits of preschool children in Hong Kong and their caregivers' dental knowledge and attitudes. Int J Paediatr Dent 2002;12:322-31.

15. Kranz AM, Rozier RG, Zeldin LP, Preisser JS. Oral health activities of early head start teachers directed toward children and parents. J Public Health Dent 2011;71:161-9.

16. Pankaj AA, Nagesh L, Pradnya H. Knowledge, attitude and practices towards oral health among anganwadi workers of Belgaum City, Karnataka. J Indian Assoc Public Health Dent 2005;5:14-6.
17. Kumari NR, Sheela S, Sarada PN. Knowledge and attitude on infant oral health among graduating medical students in Kerala. J Indian Soc Pedod Prev Dent 2006;24:173-6.

18. Schroth RJ, Brothwell DJ, Moffatt ME. Caregiver knowledge and attitudes of preschool oral health and early childhood caries (ECC). Int J Circumpolar Health 2007;66:153-67.

19. Poornima K, Reddy CV, Shivakumar BN, Vidya M. A study to assess the knowledge, attitude and practices towards oral health among anganwadi workers of Mysore city. J Indian Assoc Public Health Dent 2011;18:167-70.

20. Ramroop V, Wright D, Naidu R. Dental health knowledge and attitudes of primary school teachers toward developing dental health education. West Indian Med J 2011;60:576-80.

21. Dawani N, Nisar N, Khan N, Syed S, Tanweer N. Oral health knowledge, attitude and self-practices of preschool teachers of Karachi, Pakistan. J Pak Dent Assoc 2013;22:47-51.

22. Vinay S, Naveen N, Naganandini N. Feeding and oral hygiene habits of children attending daycare centres in Bangalore and their caretakers oral health knowledge, attitude and practices. Indian J Dent Res 2011;22:561-6. 